ARTICLE

\title{
Important Remarks on Latest Multigroup Libraries
}

\author{
Chikara KONNO*, Kosuke TAKAKURA, Keitaro KONDO, \\ Seiki OHNISHI, Kentaro OCHIAI and Satoshi SATO
}

Japan Atomic Energy Agency, 2-4 Shirakata, Tokai-mura, Naka-gun, Ibaraki-ken, 319-1195, Japan

\begin{abstract}
We have already pointed out that the background cross sections and weighting flux are not adequate in the multigroup library VITAMIN-B6. Here we examine whether the latest multigroup libraries, VITENEA-J, VITJEFF31.BOLIB, MATJEFF31.BOLIB, V7-200N47G in SCALE6, MATXS file in ADS-2.0, HILO2k and MATXSLIB-J33, have the same problems or not. The followings are found out from simple benchmark calculations with ANISN; 1) MATXSLIB-J33 has no problem, 2) VITENEA-J, VITJEFF31.BOLIB, V7-200N47G in SCALE6 and HILO2k are produced by using an inadequate weighting flux, 3) VITJEFF31.BOLIB, MATJEFF31.BOLIB and MATXS file in ADS-2.0 have insufficient background cross section data. It is noted that the self-shielding correction in VITENEA-J, VITJEFF31.BOLIB, MATJEFF31.BOLIB, V7-200N47G in SCALE6, MATXS file in ADS-2.0 and HILO2k is not always adequate, which can lead to unexpected results.
\end{abstract}

KEYWORDS: multigroup library, self-shielding correction, background cross section, weighting flux, ANISN

\section{Introduction}

Recently Monte Carlo calculations are very popular in nuclear analyses and designs, but deterministic calculations with discrete ordinate codes are still carried out because the calculation time for deterministic calculations is much shorter than that for Monte Carlo calculations. The deterministic calculations use mutigroup libraries, which include several approximations. The approximations are sometimes inadequate, particularly for self-shielding correction, the deterministic calculation results with which are sometimes different from the Monte Carlo calculation results.

We have already pointed out ${ }^{1)}$ that the multigroup library VITAMIN-B $6^{2)}$ has the following inadequate treatments, which lead to insufficient self-shielding correction.

1) The smallest background cross section is larger than that required in natural iron.

2) The weighting flux of $1 /\left(\sigma_{t}+\sigma_{0}\right)$, where $\sigma_{t}$ is the total cross section and $\sigma_{0}$ is the background cross section, is adopted, not the weighting flux of $1 /\left(\sigma_{t}+\sigma_{0}\right)^{\ell+1}$, where $\ell$ is the Legendre expansion order.

In this paper we examine whether the latest multigroup libraries (VITENEA-J, ${ }^{3)}$ VITJEFF31.BOLIB, ${ }^{4}$ MATJEFF31. BOLIB, ${ }^{5)} \mathrm{V7-200N47G}$ in SCALE6, ${ }^{6}$ MATXS file in ADS-2.0, ${ }^{7)}$ HILO2 $\mathrm{k}^{8)}$ and MATXSLIB-J33 ${ }^{9)}$ ) have the same problems or not.

\section{Review of Problems in VITAMIN-B6}

The multigroup library VITAMIN-B6 released from ORNL in 1996 is an AMPX master file ${ }^{6)}$ of ENDF/B-VI release $3 .^{10)}$ The group structure is 199 groups for neutron and 42 groups for gamma. The problems in VITAMIN-B6

*Corresponding author, E-mail:konno.chikara@jaea.go.jp

(C) 2011 Atomic Energy Society of Japan, All Rights Reserved. have been reported in Reference 1 . Here we would like to introduce them briefly.

It all started with a simple benchmark calculation with VITAMIN-B6. The calculation model consisted of a natural iron sphere of $1 \mathrm{~m}$ in radius with an isotropic neutron source of $17.332-19.64 \mathrm{MeV}$, which is the first group in VITAMIN-B6, in the center as shown in Fig. 1. Neutron spectra in the sphere were calculated with the $\mathrm{Sn}$ code ANISN $^{11)}$ and an ANISN formatted multigroup library ${ }^{11)}$

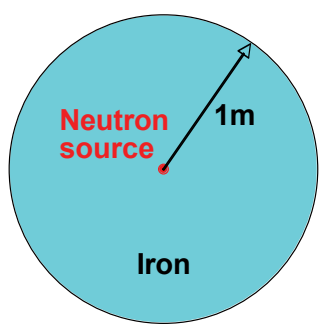

Fig. 1 Calculation model for simple benchmark test

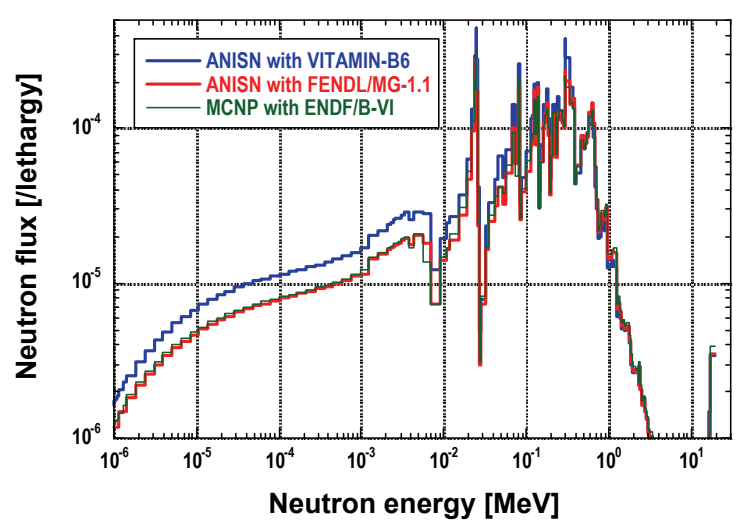

Fig. 2 Neutron spectra at $40 \mathrm{~cm}$ from center of iron sphere 
produced from VITAMIN-B6 by using SCALE6.0. For comparison we also carried out another ANISN calculation with an ANISN formatted multigroup library ${ }^{11)}$ produced from FENDL/MG-1.1, ${ }^{12}$ which was a MATXS file ${ }^{13)}$ for FENDL-1.1 ${ }^{14)}$ and iron data of which were taken from ENDF/B-VI, by using the TRANSX ${ }^{13)}$ code. Moreover a calculation with MCNP4C ${ }^{15)}$ and ENDF/B-VI was carried out as a reference.

Figure 2 shows the calculated neutron spectra at the distance of $40 \mathrm{~cm}$ from the center of the iron sphere. The neutron spectrum below $10 \mathrm{keV}$ with ANISN and VITAMIN-B6 is by at most $50 \%$ larger than that with MCNP, while that with ANISN and FENDL/MG-1.1 agrees with that with MCNP.

From detailed investigation on VITAMIN-B6, it was found out that the following two problems caused the above discrepancy in the neutron flux below $10 \mathrm{keV}$.

One problem is the background cross section. In the Bondarenko method $^{13)}$ for the self-shielding correction, the following weighting flux should be used for averaging cross section data in a group,

$$
W_{\ell}(E)=\frac{C(E)}{\left[\sigma_{0}+\sigma_{t}(E)\right]^{\ell+1}},
$$

where $C(E)$ is the smooth part of the shape of the flux, $\sigma_{0}$ is called the background cross section, $\sigma_{t}(E)$ is the total cross section and $\ell$ is the Legendre expansion order. The background cross section data in ${ }^{56} \mathrm{Fe}$ of VITAMIN-B6 are $10^{10}, 10^{5}, 10^{3}, 10^{2}, 50,10$ and 1 barn, but natural iron requires the background cross section of approximately 0.2 barn for ${ }^{56} \mathrm{Fe}$. The self-shielding effect is corrected by using the background cross section data of 1 barn for ${ }^{56} \mathrm{Fe}$ in VITAMIN-B6, which leads to insufficient self-shielding correction.

The other problem is the weighting flux. The weighting flux in Eq. (1) should be used for adequately averaging cross section data in a group. However the weighting fluxes for $\ell \geq 1$ used in VITAMIN-B6 and FENDL/MG-1.1 are the followings and are different from Eq. (1),

$$
\begin{aligned}
& W_{\ell \geq 1}(E)=W_{0}(E) \text { in VITAMIN-B6, } \\
& W_{\ell \geq 1}(E)=W_{1}(E) \quad \text { in FENDL/MG-1.1. }
\end{aligned}
$$

We have to remember that the $\mathrm{S}_{\mathrm{N}}$ multigroup cross section data for discrete ordinates codes are not the same as the $\mathrm{P}_{\mathrm{N}}$ multigroup cross section data which are included in VITAMIN-B6 and FENDL/MG-1.1. The relation between the $\mathrm{S}_{\mathrm{N}}$ and $\mathrm{P}_{\mathrm{N}}$ multigroup cross section data is following, ${ }^{13)}$

$$
\begin{aligned}
& \sigma_{\ell t g}^{P N}=\frac{\int_{g} \sigma_{t}(E) W_{\ell}(E) d E}{\int_{g} W_{\ell}(E) d E}, \\
& \sigma_{\ell g \leftarrow g^{\prime}}^{P N}=\frac{\int_{g^{\prime}} d E^{\prime} \int_{g} \sigma_{\ell}\left(E^{\prime} \rightarrow E\right) W_{\ell}\left(E^{\prime}\right) d E}{\int_{g^{\prime}} W_{\ell}\left(E^{\prime}\right) d E^{\prime}}, \\
& \sigma_{\ell g \leftarrow g^{\prime}}^{S N}=\sigma_{\ell g \leftarrow g^{\prime}}^{P N} \text { for } g \neq g^{\prime}, \\
& \sigma_{\ell g \leftarrow g}^{S N}=\sigma_{\ell g \leftarrow g}^{P N}-\left(\sigma_{\ell t g}^{P N}-\sigma_{0 t g}^{P N}\right)-\Delta_{g}^{N}, \\
& \sigma_{g}^{S N}=\sigma_{0 t g}^{P N}-\Delta_{g}^{N},
\end{aligned}
$$

where $\sigma_{\ell}\left(E^{\prime} \rightarrow E\right)$ is the scattering cross section and $\Delta_{g}^{N}$ can be chosen to minimize the effects of truncating the Legendre expansion at $\ell=N$. " $\Delta_{g}^{N}=0$ " is often chosen, which is called "Consistent-P approximation". In this case, Eqs. (7) and (8) become

$$
\begin{aligned}
& \sigma_{\ell g \leftarrow g}^{S N}=\sigma_{\ell g \leftarrow g}^{P N}-\left(\sigma_{\ell t g}^{P N}-\sigma_{0 t g}^{P N}\right), \\
& \sigma_{g}^{S N}=\sigma_{0 t g}^{P N} .
\end{aligned}
$$

The difference between the $\mathrm{S}_{\mathrm{N}}$ and $\mathrm{P}_{\mathrm{N}}$ multigroup cross section data appears only in Eq. (9). The term in parentheses of the right hand side in Eq. (9) is always zero in VITAMIN-B6 because of Eq. (2), which leads to $\sigma_{\ell g \leftarrow g}^{S N}=\sigma_{\ell g \leftarrow g}^{P N}$. However it is not always zero for resonance regions in FENDL/MG-1.1 because of Eq. (3), which leads to $\sigma_{\ell g \leftarrow g}^{S N} \neq \sigma_{\ell g \leftarrow g}^{P N}$, while it is almost zero for non-resonance regions because the weighting flux has a smooth shape in non-resonance regions, which leads to $\sigma_{\ell g \leftarrow g}^{S N} \approx \sigma_{\ell g \leftarrow g}^{P N}$. The weighting flux for $\ell \geq 2$ in Eq. (3) is different from that in Eq. (1), but it was demonstrated in Reference 1 that its influence is small.

\section{Analysis}

The simple benchmark calculation described in Section II was adopted. The material was basically natural iron, but it was changed if problems occurred in other materials. Neutron spectra inside the sphere were calculated with ANISN and MCNP4C. The following mutigroup libraries were examined.

\section{$\checkmark$ VITENEA-J (AMPX master file) \\ $\checkmark$ VITJEFF31.BOLIB (AMPX master file) \\ $\checkmark$ MATJEFF31.BOLIB (MATXS file) \\ $\checkmark$ V7-200N47G in SCALE6.0 (AMPX master file) \\ $\checkmark$ MATXS file in ADS-2.0 (MATXS file) \\ $\checkmark$ HILO2k (ANISN formatted file) \\ $\checkmark$ MATXSLIB-J33 (MATXS file)}

The AMPX master files were converted to ANISN formatted libraries with SCALE6.0, while the MATXS files were converted to ANISN formatted libraries with TRANSX. The self-shielding effect was corrected. Corresponding official ACE files (FENDL/MC-2.0, ${ }^{16)}$ MCJEFF3.1NEA, ${ }^{17}$ ) MCNP data, ${ }^{18)}$ FSXLIB-J33 ${ }^{9}$ ) were adopted in the MCNP calculations. The multigroup libraries were reviewed through the comparison between neutron spectra calculated with ANISN and MCNP.

\section{Results and Discussion}

\section{VITENEA-J}

VITENEA-J is an AMPX master file of mainly FENDL-2.0 ${ }^{19)}$ and partly ENDF/B-VI released from ENEA/Bologna in 2004. The group structure is 175 groups for neutron and 42 groups for gamma. The background cross section data are no problem because the smallest background cross section is $10^{-6}$ barn. However the self-shielding correction is not always adequate as shown in Fig. 3 because the weighting flux of Eq. (2) is adopted. 


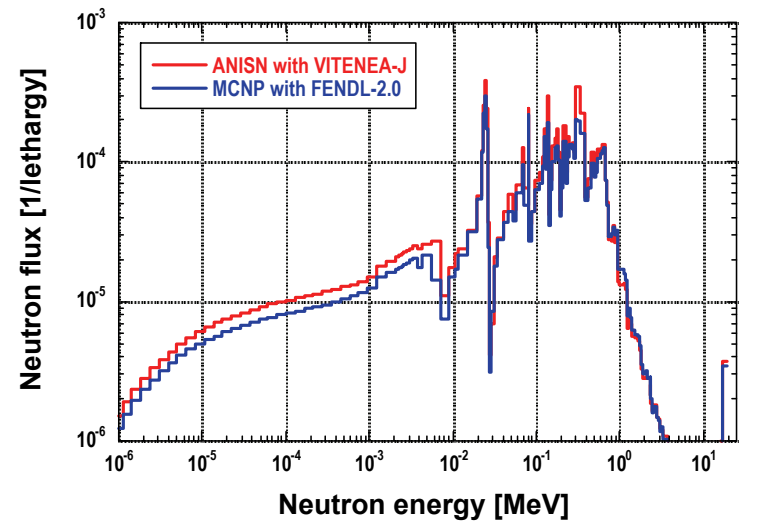

Fig. 3 Neutron spectra at $40 \mathrm{~cm}$ from center of iron sphere

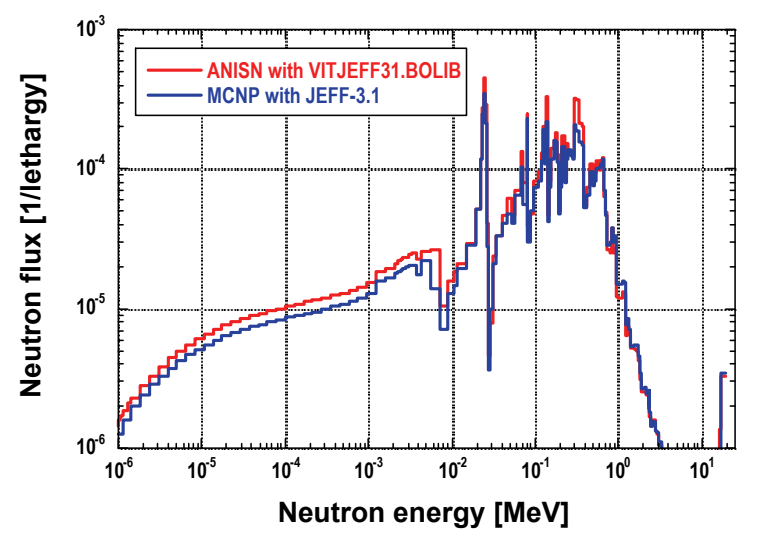

Fig. 4 Neutron spectra at $40 \mathrm{~cm}$ from center of iron sphere

\section{VITJEFF31.BOLIB}

VITJEFF31.BOLIB is an AMPX master file of JEFF-3.1 ${ }^{20)}$ released from ENEA/Bologna in 2008. The group structure is 199 groups for neutron and 42 groups for gamma. The smallest background cross section is 0.01 barn only for ${ }^{56} \mathrm{Fe}$, but it is 1 barn for other nuclei. The background cross section data are no problem for ${ }^{56} \mathrm{Fe}$, while they cause insufficient self-shielding correction for pure materials with one isotope such as cobalt. The self-shielding correction is not always adequate for both ${ }^{56} \mathrm{Fe}$ and other nuclei because the weighting flux of Eq. (2) is adopted. Examples of the insufficient self-shielding correction are shown in Fig. 4, which is very similar to Fig. 3, and Fig. 5.

\section{MATJEFF31.BOLIB}

MATJEFF31.BOLIB is a MATXS file of JEFF-3.1 released from ENEA/Bologna in 2009. The group structure is 199 groups for neutron and 42 groups for gamma. The background cross section data are the same as those in VITJEFF31.BOLIB, while the weighting flux is not Eq. (2) but Eq. (3). Thus the self-shielding correction in MATJEFF31.BOLIB is not always adequate because of the insufficient background cross section data. Typical results are shown in Fig. 6, which demonstrates that the self-shielding correction is no problem for natural iron, and Fig. 7, which indicates that the self-shielding correction is insufficient for natural cobalt.

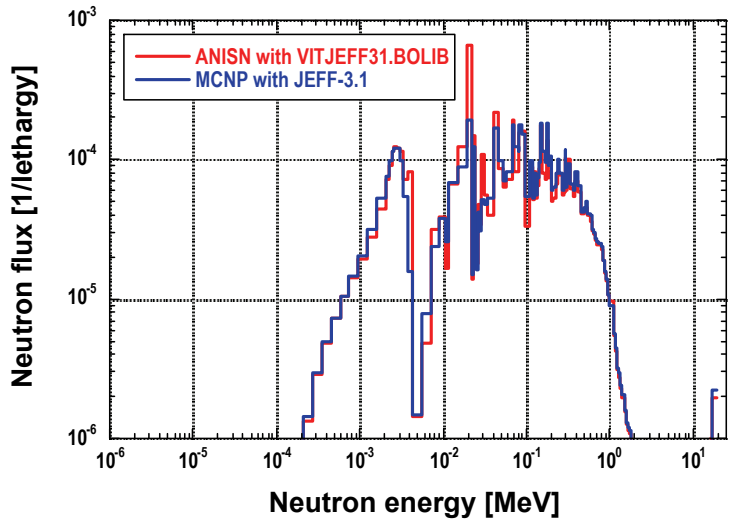

Fig. 5 Neutron spectra at $40 \mathrm{~cm}$ from center of cobalt sphere

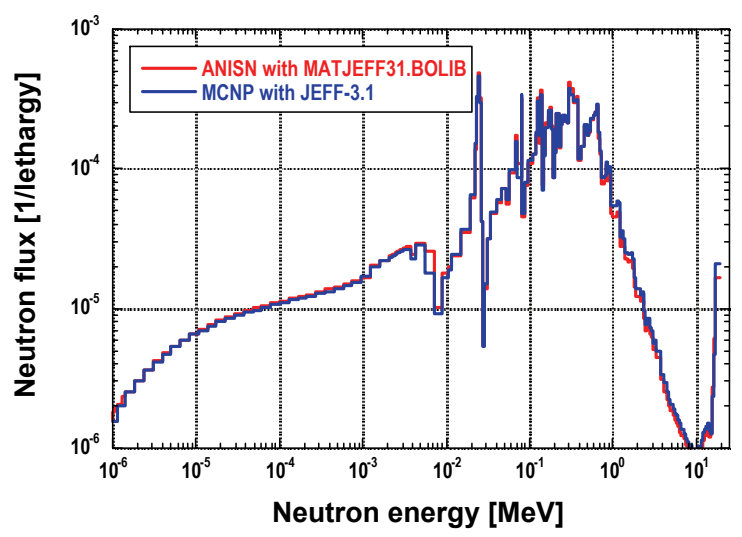

Fig. 6 Neutron spectra at $40 \mathrm{~cm}$ from center of iron sphere

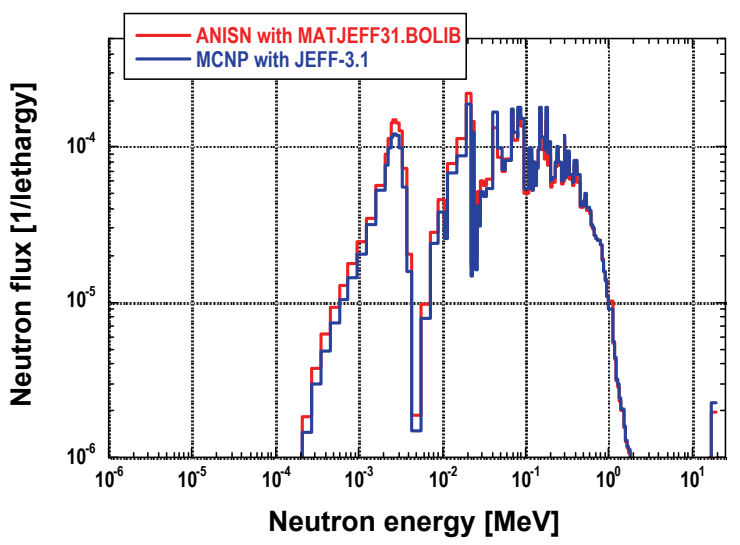

Fig. 7 Neutron spectra at $40 \mathrm{~cm}$ from center of cobalt sphere

\section{V7-200N47G in SCALE6.0}

V7-200N47G in SCALE6.0 is one of the SCALE multigroup cross-section libraries, ${ }^{6}$ ) which is an AMPX master file of ENDF/B-VII.0 ${ }^{21)}$ released from ORNL in 2009. The group structure is 200 groups for neutron and 47 groups for gamma. The background cross section data have no problem because the smallest background cross section is $10^{-6}$ barn. However the self-shielding correction is not always sufficient as shown in Fig. 8 because the weighting flux is Eq. (2). Note that other AMPX files (V5-238, V5-44, V6-238, $\mathrm{V} 7-238$ and $\mathrm{V} 7-27 \mathrm{~N} 19 \mathrm{G}$ ) in the SCALE cross-section libraries have the same problem. 


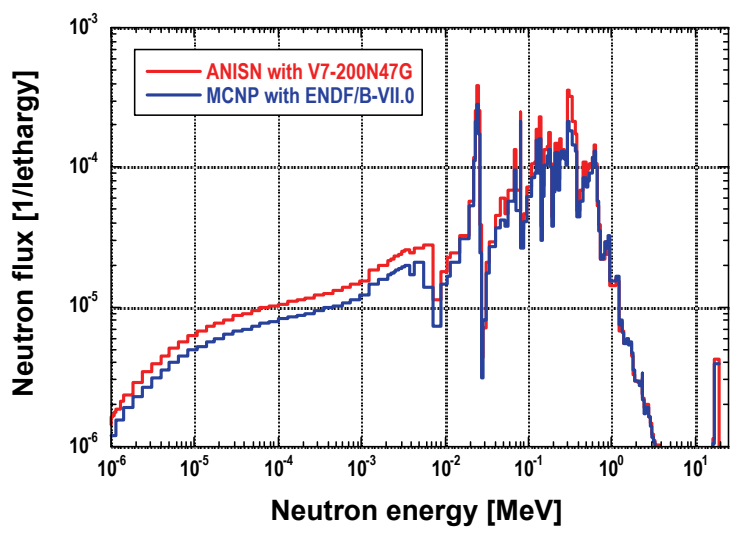

Fig. 8 Neutron spectra at $40 \mathrm{~cm}$ from center of iron sphere

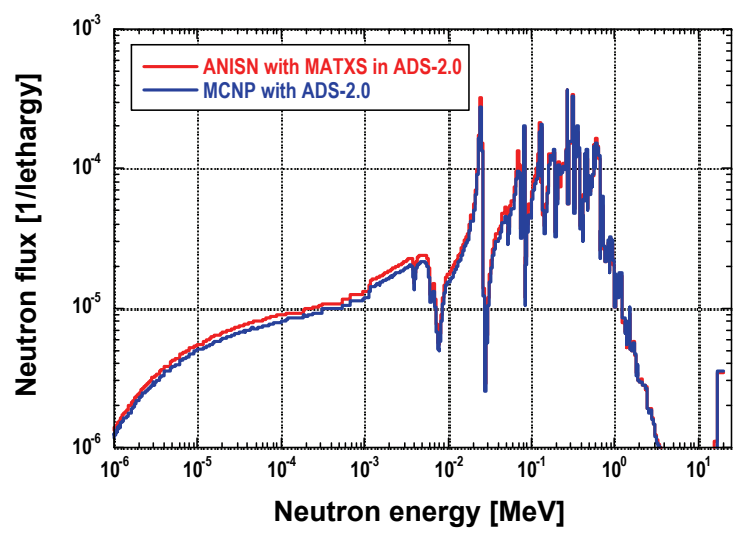

Fig. 9 Neutron spectra at $40 \mathrm{~cm}$ from center of iron sphere

\section{MATXS file in ADS-2.0}

ADS-2.0 is a test nuclear data library for accelerator driven systems and new reactor designs released from IAEA in 2008. The nuclear data of 156 materials were selected from mainly ENDF/B-VII.0 and partly JENDL/AC ${ }^{22)}$ and IAEA NDS project. ${ }^{23)}$ ADS-2.0 also includes ACE and MATXS files. The group structure of the MATXS file in ADS-2.0 is 421 groups for neutron. The background cross section data are not always adequate because the smallest background cross section is 1 barn, while the weighting flux is no problem because the weighting flux of Eq. (3) is adopted. As a result, the self-shielding correction is not always sufficient as shown in Fig. 9 though the difference between the neutron spectra with ANISN and MCNP is not so large because the group structure is very fine.

\section{HILO2k}

HILO2k is an ANISN formatted multigroup library for neutron and gamma energies up to $2 \mathrm{GeV}$ (83 groups) and $20 \mathrm{MeV}$ (22 groups), respectively. The nuclides included in HILO2k are ${ }^{1} \mathrm{H},{ }^{2} \mathrm{H}, \mathrm{He}, \mathrm{Be},{ }^{10} \mathrm{~B},{ }^{11} \mathrm{~B}, \mathrm{C}, \mathrm{N}, \mathrm{O}, \mathrm{Na}, \mathrm{Mg}, \mathrm{Al}$, $\mathrm{Si}, \mathrm{S}, \mathrm{K}, \mathrm{Ca}, \mathrm{Cr}, \mathrm{Mn}, \mathrm{Fe}, \mathrm{Ni}, \mathrm{Cu}, \mathrm{Zr}, \mathrm{Nb}, \mathrm{Cd}, \mathrm{Ba}, \mathrm{Gd}, \mathrm{Ta}, \mathrm{W}$, $\mathrm{Hg}, \mathrm{Pb},{ }^{235} \mathrm{U}$ and ${ }^{238} \mathrm{U}$. The neutron $(>20 \mathrm{MeV})$ cross sections [42 groups] are based on data calculated with MCNPX. ${ }^{18)}$ The nonelastic scattering cross sections of ${ }^{2} \mathrm{H}, \mathrm{C}$, $\mathrm{N}, \mathrm{O}, \mathrm{Al}, \mathrm{Si}, \mathrm{Ca}, \mathrm{Cr}, \mathrm{Fe}, \mathrm{Ni}, \mathrm{Cu}, \mathrm{Nb}, \mathrm{W}$ and $\mathrm{Pb}$ are normalized to those in LA150. ${ }^{21)}$ On the contrary, the neutron $(<20 \mathrm{MeV})$ [41 groups] and gamma cross sections are obtained by collapsing VITAMIN-B6, except for Fe, which

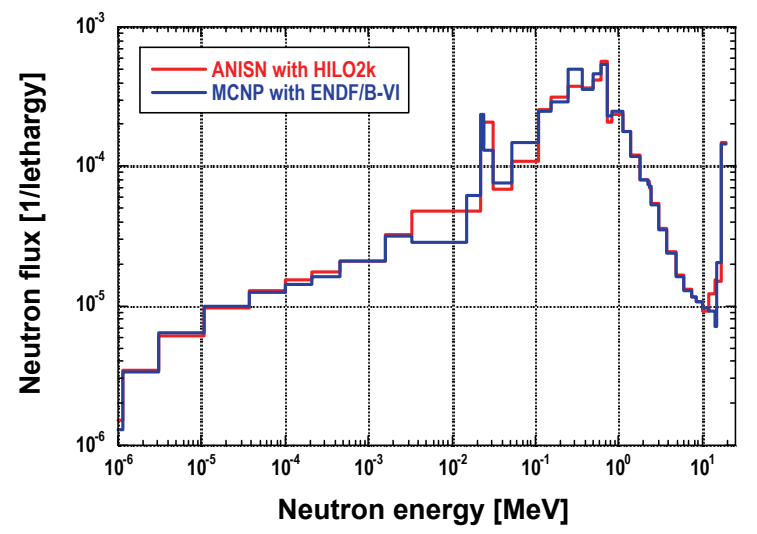

Fig. 10 Neutron spectra at $20 \mathrm{~cm}$ from center of iron sphere

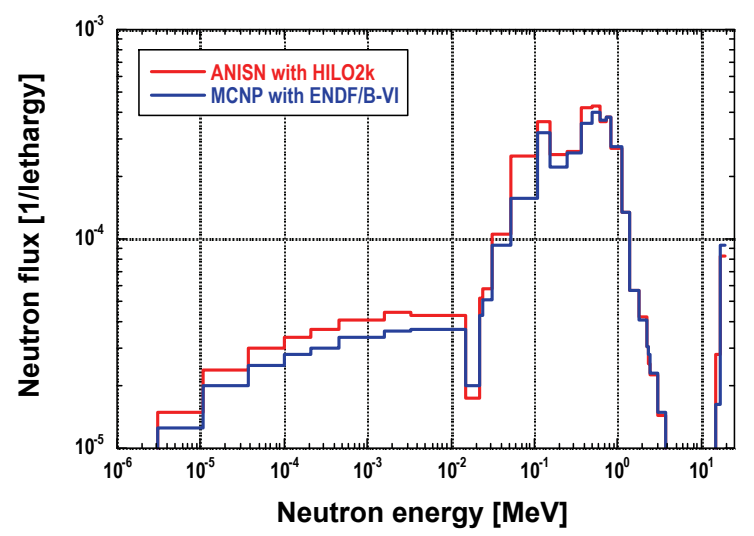

Fig. 11 Neutron spectra at $20 \mathrm{~cm}$ from center of nickel sphere

was generated based on a MATXS file. Thus HILO2k except for Fe has the same problems as VITAMIN-B6. The Fe data in HILO2k has the smallest background cross section of $10^{-6}$ barn and is generated with the weighting flux of Eq. (3). As a result, the Fe data in HILO2k has no problem as shown in Fig. 10, while other data have problems as shown in Fig. 11. Note that the energy of the isotropic neutron source in the center is set to $16.91-19.64 \mathrm{MeV}$, which is the $43 \mathrm{rd}$ group in HILO2k, in this benchmark test.

\section{MATXSLIB-J33}

MATXSLIB-J33 is a MATXS file of JENDL-3.3 ${ }^{24)}$ released from JAERI in 2003. The group structure is 175 groups for neutron and 42 groups for gamma. The background cross sections are no problem because the smallest background cross section is $10^{-5}$ barn. The weighting flux is also no problem because the weighting flux is Eq. (3). Thus the self-shielding correction is sufficient as shown in Fig. 12.

\section{Conclusion}

We reviewed whether the latest multigroup libraries (VITENEA-J, VITJEFF31.BOLIB, MATJEFF31.BOLIB, V7-200N47G in SCALE6, MATXS file in ADS-2.0, HILO2k and MATXSLIB-J33) have problems of the background cross section and the weighting flux pointed out for VITAMIN-B6, which lead to insufficient self-shielding correction, through simple benchmark calculations. As a result, 


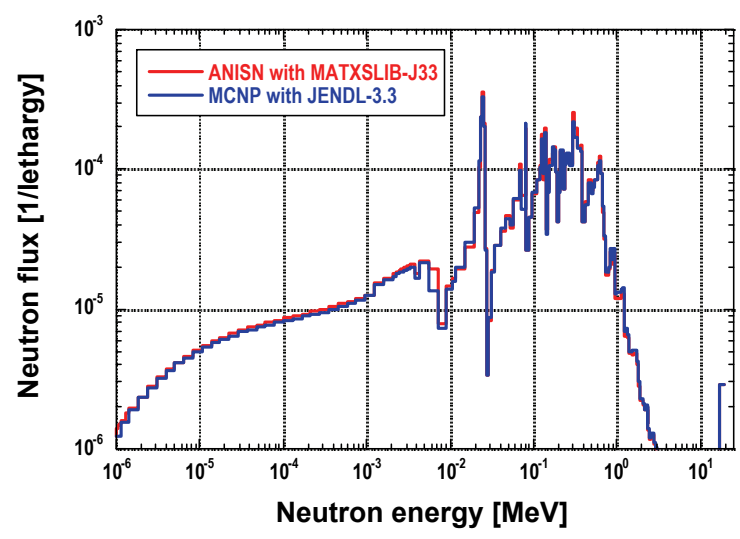

Fig. 12 Neutron spectra at $40 \mathrm{~cm}$ from center of iron sphere

the followings are found out.

1) VITENEA-J, VITJEFF31.BOLIB, V7-200N47G in SCALE6 and HILO2k (except Fe) are produced by using an inadequate weighting flux.

2) VITJEFF31.BOLIB (except ${ }^{56} \mathrm{Fe}$ ), MATJEFF31.BOLIB, MATXS file in ADS-2.0 and HILO2k (except Fe) have inadequate background cross section data.

It is demonstrated that these problems can cause insufficient self-shielding correction and can lead to unexpected calculation results. These problems should be improved based on this study in order not to cause unexpected results.

\section{References}

1) C. Konno, K. Ochiai, S. Ohnishi, "Insufficient self-shielding correction in VITAMIN-B6," Prog. Nucl. Sci. Technol., 1, 32-35 (2011).

2) J. E. White, D. T. Ingersoll, J. E. White, R. Q. Wright, H. T. Hunter, C. O. Slater, N. M. Greene, R. E. MacFarlane, R. W. Roussin, Production and testing of the VITAMIN-B6 fine-group and the BUGLE-93 broad-group neutron/photon cross-section libraries derived from ENDF/B-VI nuclear data, ORNL-6795, NUREG/CR-6214, Oak Ridge National Laboratory (ORNL) (1995).

3) D. G. Cepraga, M. Frisoni, G.. Cambi, VITENEA-J: a multigroup coupled (175n-42gamma) cross section library in AMPX format for nuclear fusion applications, RTI/FIS /MET/2004/2, ENEA (2004).

4) M. Pescarini, V. Sinitsa, R. Orsi, VITJEFF31.BOLIB - a JEFF-3.1 multi-group coupled (199 $n+42$ gamma) cross section library in AMPX format for nuclear fission applications, ENEA Internal Report FPN-P9H6-007, ENEA (2008).

5) M. Pescarini, V. Sinitsa, R. Orsi, MATJEFF31.BOLIB - a JEFF-3.1 multi-group coupled (199 $n+42$ gamma) cross section library in MATXS format for nuclear fission applications, ENEA Internal Report FPN-P9H6-014, ENEA (2009).

6) SCALE: A modular code system for performing standardized computer analyses for licensing evaluation, ORNL/TM-2005/39, Version 6, Vols. I-III, Oak Ridge National Laboratory (ORNL) (2009).

7) D. L. Aldama, A. L. Nichols, $A D S-2.0$, INDC(NDS)-0545, International Atomic Energy Agency (IAEA) (2008).

8) HILO2k, RSICC DATA LIBRARY DLC-220 (2004).

9) K. Kosako, N. Yamano, T. Fukahori, K. Shibata, A. Hasegawa, The libraries FSXLIB and MATXSLIB based on JENDL-3.3, JAERI-Data/Code 2003-011, Japan Atomic Energy Research Institute (JAERI) (2003).
10) P. F. Rose, ENDF/B-VI summary documentation, BNL-NCS-17541 (ENDF-201), Brookhaven National Laboratory (BNL) (1991).

11) DOORS3.2a: One, two- and three-dimensional discrete ordinates neutron/photon transport code system, RSICC CODE PACKAGE CCC-650 (2007).

12) R. E. MacFarlane, FENDL/MG, library of multigroup cross-sections in GENDF and MATXS format for neutron-photon transport calculations, version 1.1 of March 1995. Summary documentation by A. B. Pashchenko, H. Wienke, S. Ganesan, IAEA-NDS-129 Rev. 3, International Atomic Energy Agency (IAEA) (1996).

13) R. E. MacFarlane, TRANSX 2: a code for interfacing MATXS cross-section libraries to nuclear transport codes, LA-12312-MS, Los Alamos National Laboratory (LANL) (1993).

14) A. B. Pashchenko, H. Wienke, S. Ganesan, P. K. McLaughlin, $F E N D L / E$, evaluated nuclear data library of neutron interaction cross sections, photon production cross sections and photon-atom interaction cross sections for fusion applications, version 1.1 of November 1994, IAEA(NDS)-128, Rev. 3, International Atomic Energy Agency (IAEA) (1996).

15) J. F. Briesmeister (Ed.), MCNP - a general Monte Carlo n-particle transport code, version 4C, LA-13709-M, Los Alamos National Laboratory (LANL) (2000).

16) $\mathrm{H}$. Wienke, M. Herman, FENDL/MG-2.0 and FENDL/MC-2.0, the processed cross section libraries for neutron-photon transport calculations, IAEA-NDS-176, Rev.1, International Atomic Energy Agency (IAEA) (1998).

17) OECD NEA Data Bank, Processing of the JEFF-3.1 cross section library into a continuous energy Monte Carlo radiation transport and criticality data library, NEA/NSC/DOC 18 (2006).

18) $M C N P 5 / M C N P X-E X E$, RSICC CODE PACKAGE CCC-740 (2009).

19) A. B. Pashchenko, H. Wienke, FENDL/E-2.0, evaluated nuclear data library of neutron nuclear interaction cross sections and photon production cross sections and photon-atom interaction cross sections for fusion applications, IAEA-NDS-175, Rev. 3, International Atomic Energy Agency (IAEA) (1998).

20) A. Koning, R. Forrest, M. Kellett, R. Mills, H. Henriksson, Y. Rugama (Ed.), The JEFF-3.1 nuclear data library, JEFF Report 21, OECD Nuclear Energy Agency (2006).

21) M. B. Chadwick, P. Oblozinsky, M. Herman, N. M. Greene, R. D. McKnight, D. L. Smith, P. G. Young, R. E. MacFarlane, G. M. Hale, S. C. Frankle, A. C. Kahler, T. Kawano, R. C. Little, D. G. Madland, P. Moller, R. D. Mosteller, P. R. Page, P. Talou, H. Trellue, M. C. White, W. B. Wilson, R. Arcilla, C. L. Dunford, S. F. Mughabghab, B. Pritychenko, D. Rochman, A. A. Sonzogni, C. R. Lubitz, T. H. Trumbull, J. P. Weinman, D. A. Brown, D. E. Cullen, D. P. Heinrichs, D. P. McNabb, H. Derrien, M. E. Dunn, N. M. Larson, L. C. Leal, A. D. Carlson, R. C. Block, J. B. Briggs, E. T. Cheng, H. C. Huria, M. L. Zerkle, K. S. Kozier, A. Courcelle, V. Pronyaev, S. C. van der Marck, "ENDF/B-VII.0 : next generation evaluated nuclear data library for nuclear science and technology," Nucl. Data Sheets, 107, 2931-3059 (2006).

22) O. Iwamoto, T. Nakagawa, N. Otuka, S. Chiba, K. Okumura, G. Chiba, T. Ohsawa, K. Furutaka, "JENDL actinoid file 2008," $J$. Nucl. Scl. Technol., 46, 510-528 (2009).

23) A. Trkov, R. Capote, I. Kodeli, L. Leal, "Evaluation of tungsten nuclear reaction data with covariances," Nucl. Data Sheets, $\mathbf{1 0 9}$, 2905-2909 (2008). 